\title{
Antioxidant Activity of Tartary (Fagopyrum tataricum (L.) Gaertn.) and Common (Fagopyrum esculentum Moench) Buckwheat Sprouts
}

\author{
Chia-Ling LiU, ${ }^{\dagger}$ Yih-Shyuan Chen, ${ }^{\dagger}$ JoAn-Hwa Yang, ${ }^{\dagger}$ AND \\ BeEn-Huang ChIANG*,*
}

\begin{abstract}
Department of Food Science, Nutrition and Nutraceutical Biotechnology, Shih Chien University, 70, Ta-chih St. Taipei 104, Taiwan, ROC and Institute of Food Science and Technology, National Taiwan University, No.1, Sec. 4, Roosevelt Road, Taipei 106, Taiwan, ROC
\end{abstract}

\begin{abstract}
This study compared the differences of two types of buckwheat sprouts, namely, common buckwheat (Fagopyrum esculentum Moench) and tartary buckwheat (Fagopyrum tataricum (L.) Gaertn.), in general composition, functional components, and antioxidant capacity. The ethanol extracts of tartary buckwheat sprouts (TBS) had higher reducing power, free radical scavenging activity, and superoxide anion scavenging activity than those of common buckwheat sprouts (CBS). As for chelating effects on ferrous ions, CBS had higher values than TBS. Rutin was the major flavonoid found in these two types of buckwheat sprouts, and TBS was 5 fold higher in rutin than CBS. The antioxidant effects of buckwheat sprouts on human hepatoma HepG2 cells revealed that both of TBS and CBS could decrease the production of intracellular peroxide and remove the intracellular superoxide anions in HepG2 cells, but TBS reduced the cellular oxidative stress more effectively than CBS, possibly because of its higher rutin (and quercetin) content.
\end{abstract}

KEYWORDS: Buckwheat sprouts; flavonoids; antioxidant capacity; HepG2 cells

\section{INTRODUCTION}

Free radicals have been found to be related to illnesses, cell damages, cell death, and gene mutation (1), and the relationship between the intake of foods containing antioxidant components and the illnesses caused by oxidative damage has become an important research topic in the food and nutrition area. Buckwheat, an important staple food consumed in Japan, Korea, Russia, and Poland, is rich in polyphenols, including six flavonoids, rutin, orientin, vitexin, quercetin, isovitexin, and isoorientin (2-6). The chemical structures of these flavonoids can be found elsewhere (4-6). Among these antioxidant components, rutin was recognized as the most health protective and has also been proven to be anti-inflammatory and anticarcinogenic. Rutin also has relaxing effects on smooth muscles (7) and is effective for preventing capillary apoplexy and retinal hemorrhage $(8,2)$.

There are two types of buckwheat, common buckwheat and tartary buckwheat. Common buckwheat, or sweet buckwheat, is usually consumed in Asia, Europe, North America, South Africa, and Australia (2), whereas tartary buckwheat is rarely consumed because of its bitter taste. However, it has been reported that the general composition of crude protein, crude

* Corresponding author. Telephone: 886-2-33662415, fax: 886-223623925, e-mail:bhchiang@ntu.edu.tw.

${ }^{\dagger}$ Shih Chien University.

¥ National Taiwan University. fiber, crude fat, and crude ash of common buckwheat and tartary buckwheat are essentially the same (9). Moreover, tartary buckwheat may even contain more bioactive components than common buckwheat. For instance, it has been reported that the flavonoid content of tartary buckwheat is higher than that of common buckwheat. The flavonoid content was $40 \mathrm{mg} / \mathrm{g}$ in tartary buckwheat seeds as compared to $10 \mathrm{mg} / \mathrm{g}$ in common buckwheat seeds (2). The comparative composition studies of common buckwheat and tartary buckwheat show higher thiamine, riboflavin, and pyridoxine contents, and they are an excellent food for use in preventative nutrition (10).

Bean sprouts, rich in dietary fibers, various nutrients, and bioactive components, are important vegetables consumed in Asian countries, and, nowadays, they have become more popular in the United States and European countries. Although the most popular bean sprouts are cultivated from mungbean and soybean, buckwheat seeds are also a good source of bean sprouts. However, little is known about buckwheat sprouts. The objective of this study was to investigate the differences between the two kinds of buckwheat sprouts, common buckwheat and tartary buckwheat, in general composition, functional components, and antioxidant capacity.

\section{MATERIALS AND METHODS}

Materials. Common buckwheat was supplied by Jingshan Farm of Taiwan, and tartary buckwheat was supplied by Erlin Farmers' Association of Changhua, Taiwan. Rutin, quercetin, quercitrin, ascorbic 
acid, potassium ferricyanide, 1,1-diphenyl-2-picrylhydrazyl (DPPH), ferrozine, $\beta$-nicotinamide adenine dinucleotide (NADH), trypsin, 3-(4,5dimethylthiazol-2-yl)-2,5-diphenyl-tetrazolium bromide (MTT), 2', $7^{\prime}$ dichlorofluorescein diacetate (DCFH-DA), dihydroethidium (DHE), and dimethyl sulfoxide (DMSO) were purchased from Sigma Chemical Co.(St. Louis, MO, USA). Trichloroacetic acid, ferric chloride, and iron chloride tetrahydrate were purchased form Kanto Chemical Co. (Tokyo, Japan). Methanol and ethanol were purchased form J.T. Baker (Phillipsburg, NJ, USA). Ammonium thiocyanate and sodium phosphate were purchased form Shimakyu Co. (Osaka, Japan). Phenazine methosulfate (PMS) and nitro blue terazolium chloride monohydrate (NBT) were purchased form Acros Organics (Phillipsburg, N. J. USA). Vitexin was purchased form Fluka Co. (Darmstadt, Germany). Pyrogallol, ethylenediaminete triacetic acid, potassium chloride, potassium dihydrogen phosphate, sodium chloride, and sodium hydrogen carbonate were purchased form Merck Co. (Santa Ana, CA, USA). Isoorientin was purchased form Chromadex Co. (Ronkonkoma, NY, USA). Isovitexin was purchased form Fluka Chemika-Biochemika Co. (Buchs SG, Switzerland). The human hepatoma cell line (HepG2 cells) was a gift from Bioinformatics Laboratory., BCRC, Food Industry Research and Development Institute (Shinzu, Taiwan). Dulbecco's Modified Eagle Medium (DMEM) was purchased from Invitrogen Corp. (Carlsbad, CA, USA). Fetal bovine serum (FBS) was purchased from Gemini Bio-Products (Woodland, CA, USA).

Cultivation of Buckwheat Sprouts. Buckwheat seeds, including common buckwheat and tartary buckwheat, were soaked in water for $6 \mathrm{~h}$ at room temperature and then put into a germination bag for germination in a shady, cool place for $12-15 \mathrm{~h}$. The potting mix was laid flat on a plate ( $35 \mathrm{~cm}$ long by $25 \mathrm{~cm}$ wide by $3 \mathrm{~cm}$ high) with a perforated bottom. Once the buckwheat seeds were germinated, they were spread evenly on the potting mix, placed in a half-day sunny location, and watered every $4 \mathrm{~h}$ until the buckwheat sprouts were grown to a length of approximately $5 \mathrm{~cm}$ in $6-7$ days. The sprouts were then harvested and immediately dried in a freeze-dryer (KINGMECH FD12-2S-6P-S, Kingmech Co., Taipei, Taiwan). The dried buckwheat sprouts were powdered by a high-speed pulverizer (250G, RT-04, Rong Tsong Precision Technology Co., Taichin, Taiwan), packed in plastic bottles, and stored in a freezer before analysis.

Composition Analysis of Buckwheat Sprouts. The ash, crude fat, crude protein, and crude fiber contents of dried samples were analyzed using the standard AOAC methods (11), and the compositions were denoted by percentage on dry basis.

Preparation of Ethanol Extracts of Buckwheat Sprouts. One hundred milliliters of $95 \%$ ethanol were added to $10 \mathrm{~g}$ of dried buckwheat powder, and the mixture was extracted by thermal reflux at $80{ }^{\circ} \mathrm{C}$ for $3 \mathrm{~h}$ and then filtered by Whatman No.1 filter paper. The above extraction was repeated twice, and the collected filtrate was evaporated at a temperature below $40{ }^{\circ} \mathrm{C}$ and dried in a freeze-dryer to remove the water. Finally, the dried extracts were stored at $-20{ }^{\circ} \mathrm{C}$.

Phenolic Compound Analyses. A moderate amount of ethanol extracts from buckwheat sprouts were weighed and dissolved in methanol (12). After filtering the solutions through $0.45 \mu \mathrm{m}$ nylon filters, samples were mixed with $1000 \mathrm{ppm}$ of pyrogallol as internal standard for analysis by HPLC (Hewlett-Packard series 1100, Agilent Technologies, Inc., Santa Clara, CA, USA). The HPLC analysis was carried out under the following conditions; the Zorbax 80A Extend C18 column $(5 \mu \mathrm{m}, 4.6 \times 250 \mathrm{~mm})$ was used with water (Mill-Q, $18.2 \mathrm{M} \Omega)$ as mobile phase A, and methanol/acetic acid $(95: 5, \mathrm{v} / \mathrm{v})$ was used as mobile phase B; the gradient elution was run with $20 \%$ of solution B at 10 min, $40 \%$ of solution B at $20 \mathrm{~min}, 50 \%$ of solution B at $30 \mathrm{~min}, 70 \%$ of solution B at $40 \mathrm{~min}, 80 \%$ of solution B at $50 \mathrm{~min}$, and $100 \%$ of solution B at $60 \mathrm{~min}$ at a flow rate of $1 \mathrm{~mL} / \mathrm{min}$; the injection volume was $5 \mu \mathrm{L}$, and a wavelength of $254 \mathrm{~nm}$ was used for detection. Pure compounds including rutin, orientin, vitexin, quercetin, quercitrin, isovitexin, and isoorientin were also analyzed by HPLC with the same conditions, and the retention time was used to identify the flavonoids in the sample.

Determination of Reducing Power. The reducing power of the ethanol extracts of buckwheat sprouts were determined according to the method described by Oyaizu (13). Various concentrations (0.3-10 $\mathrm{mg} / \mathrm{mL}$ ) of the ethanol solutions of the buckwheat sprouts extracts and ascorbic acid were prepared, and $1 \mathrm{~mL}$ of each was mixed with $1 \mathrm{~mL}$ of $0.2 \mathrm{M}$ phosphate buffer, $\mathrm{pH} 6.6$, and $1 \mathrm{~mL}$ of $1 \%$ potassium ferricyanide $\left[\mathrm{K}_{3} \mathrm{Fe}(\mathrm{CN})_{6}\right]$. The mixture was then incubated at $50{ }^{\circ} \mathrm{C}$ for $20 \mathrm{~min}$. The resulting solution was cooled down rapidly, spiked with $1 \mathrm{~mL}$ of $10 \%$ trichloroacetic acid and centrifuged at $1400 \mathrm{~g}$ for 10 min. After centrifugation, $1 \mathrm{~mL}$ of supernatant was mixed with $1 \mathrm{~mL}$ of distilled water and $0.5 \mathrm{~mL}$ of $0.1 \%$ ferric chloride, and the absorbance was measured at $700 \mathrm{~nm}$ using a spectrophotometer. Increased absorbance of the reaction mixture indicated increased reducing power.

Determination of Free Radical Scavenging Activity. The effect of ethanol extracts of buckwheat sprouts on the DPPH radical scavenging activity was measured according to the method stated by Shimada et al. (14). Various concentrations $(0.3-10 \mathrm{mg} / \mathrm{mL})$ of the ethanol solutions of the buckwheat sprouts extracts and ascorbic acid were prepared, and $4 \mathrm{~mL}$ of each was mixed with $1 \mathrm{~mL}$ of freshly prepared $1 \mathrm{mM}$ DPPH methanol solution. The solution without adding the DPPH solution served as a blank. The resulting solutions were then left to stand at room temperature for $30 \mathrm{~min}$ prior to being spectrophotometrically detected at $517 \mathrm{~nm}$. Lower absorbance of the reaction mixture indicated higher free radical scavenging activity. The percentage of DPPH scavenging activity was expressed by $\{1-$ [test sample absorbance - blank sample absorbance)/blank sample absorbance]\} $\times 100 \%$.

Determination of Metal Chelating Effect. The ferrous ions chelating effect was measured according to the method described by Dinis, Madeira, and Almeida (15). Various concentrations (0.3-10 mg/ $\mathrm{mL}$ ) of the ethanol solutions of the buckwheat sprouts extracts and ascorbic acid were prepared, and $2 \mathrm{~mL}$ of each was added to $0.1 \mathrm{~mL}$ of $1 \mathrm{mM} \mathrm{FeCl}_{2}$ solution. The reaction was initiated by the addition of $0.2 \mathrm{~mL}$ of $2.5 \mathrm{mM}$ ferrozine, shaken vigorously, and then left standing at room temperature for $10 \mathrm{~min}$. The absorbance of solution was then measured spectrophotometrically at $562 \mathrm{~nm}$. The percentage of ferrous ion chelating effect was expressed by [1 - (test sample absorbance/ blank sample absorbance) $] \times 100 \%$.

Determination of Superoxide Anion Scavenging Activity. The superoxide anion scavenging activity was measured based on the method described by Liu, Ooi, and Chang (16) with slight modification. Various concentrations $(0.3-10 \mathrm{mg} / \mathrm{mL})$ of the ethanol solutions of the buckwheat sprout extracts and ascorbic acid were prepared. One milliliter of NBT solution (156 $\mu \mathrm{M}$ NBT in $100 \mathrm{mM}$ phosphate buffer, $\mathrm{pH} 7.4), 1 \mathrm{~mL}$ of NADH solution ( $468 \mu \mathrm{M}$ in $100 \mathrm{mM}$ phosphate buffer, $\mathrm{pH}$ 7.4), and $0.1 \mathrm{~mL}$ of each of the prepared ethanol solutions were mixed. After adding $100 \mu \mathrm{L}$ of PMS solution (60 $\mu \mathrm{M}$ PMS in 100 $\mathrm{mM}$ phosphate buffer, $\mathrm{pH}$ 7.4) to the mixture, the reaction mixture was incubated at $25^{\circ} \mathrm{C}$ for $5 \mathrm{~min}$, and the absorbance at $560 \mathrm{~nm}$ was measured against blank samples. Decreased absorbance of the reaction mixture indicated increased superoxide anion scavenging activity. The percentage inhibition of superoxide anion production was expressed by $[1-$ (test sample absorbance/blank sample absorbance) $] \times$ $100 \%$.

Culture and Harvest of Human Hepatoma Cell Line. HepG2 cells were cultured with DMEM with $10 \%$ FBS in a T75 flask at $37^{\circ} \mathrm{C}, 5 \%$ $\mathrm{CO}_{2}$, and $90 \%$ relative humidity. To harvest cells, HepG2 cells were washed with PBS buffer and treated with $4 \mathrm{~mL}$ of trypsin-EDTA for $3 \mathrm{~min}$. The reaction was stopped by adding $8 \mathrm{~mL}$ of DMEM with $10 \%$ FBS. The mixture was then transferred into a tube and centrifuged at $200 \mathrm{~g}$ at room temperature for $5 \mathrm{~min}$. After removing the supernatant, cell pellet was resuspended in $4 \mathrm{~mL}$ of DMEM with $10 \%$ FBS.

Cell Survival Test (MTT Assay). HepG2 cells (with an initial concentration of $1 \times 10^{4}$ cells/well) were transferred and cultured into a 96-well plate at $37{ }^{\circ} \mathrm{C}$ and $5 \% \mathrm{CO}_{2}$ for $24 \mathrm{~h}$. A $100 \mu \mathrm{l}$ portion of buckwheat sprout ethanol extract (at $0.05-1 \mathrm{mg} / \mathrm{ml}$ ) was then added to each well, and the mixture was incubated for $24 \mathrm{~h}$. The incubation medium was then replaced with $100 \mu \mathrm{l}$ of $2 \mathrm{mg} / \mathrm{mL}$ MTT (in PBS), and cells were incubated at $37{ }^{\circ} \mathrm{C}$ and $5 \% \mathrm{CO}_{2}$ for another $2.5 \mathrm{~h}$. The MTT solution was then removed, $100 \mu \mathrm{l}$ of DMSO was added into each well, and cells were incubated for $15 \mathrm{~min}$ in the dark. Finally, the absorbance of the cell sample was measured at $570 \mathrm{~nm}$ with an ELISA reader (Tecan Spectra, Wetzlar, Germany). 
Table 1. General Composition of CBS and TBS

\begin{tabular}{cccccc}
\hline components $(\%)^{a}$ & water & crude ash & crude fat & crude protein & crude fiber \\
\hline CBS & $92.80 \pm 0.85 \mathrm{a}$ & $0.68 \pm 0.01 \mathrm{a}$ & $0.38 \pm 0.03 \mathrm{a}$ & $0.17 \pm 0.01 \mathrm{a}$ & $0.70 \pm 0.17 \mathrm{a}$ \\
TBS & $92.34 \pm 0.41 \mathrm{a}$ & $0.49 \pm 0.01 \mathrm{~b}$ & $0.31 \pm 0.02 \mathrm{~b}$ & $0.14 \pm 0.01 \mathrm{~b}$ & $0.73 \pm 0.10 \mathrm{~b}$
\end{tabular}

\footnotetext{
${ }^{a}$ Each value was expressed as the mean \pm standard deviation $(n=3)$. Components were presented based on fresh weight. Values within a column superscripted with different letters were significantly different $(P<0.05)$.
}

Determination of Intracellular Peroxide in HepG2 Cells. HepG2 cells (with an initial concentration of $4 \times 10^{6}$ cells/well) were transferred and cultured in a $6 \mathrm{~cm}^{2}$ dish at $37{ }^{\circ} \mathrm{C}$ and $5 \% \mathrm{CO}_{2}$ for $24 \mathrm{~h}$. Five milliliters of $0.5 \mathrm{mg} / \mathrm{mL}$ of buckwheat sprout ethanol extract was added into the dish, and then the contents were incubated at $37^{\circ} \mathrm{C}$ and $5 \% \mathrm{CO}_{2}$ for $12 \mathrm{~h}$. At $3,6,9$, and $12 \mathrm{~h}$, incubated solution was removed, $2 \mathrm{~mL}$ of $10 \mu \mathrm{M}$ of DCFH-DA was added, and the sample was incubated for $30 \mathrm{~min}$. The cells were then washed with PBS buffer, trypsinized, centrifuged, and resuspended in $0.7 \mathrm{~mL}$ of PBS buffer. To measure the intracellular peroxide, cell samples were analyzed at $485 \mathrm{~nm}$ by FACS Calibur (Becton Dickinson, San Diego, CA) equipped with Cell Quest software.

Determination of Intracellular Superoxide Anions in HepG2 Cells. HepG2 cells were cultured and treated with the ethanol extracts of buckwheat sprouts for $3,6,9$, and $12 \mathrm{~h}$, followed by the procedures described above. For measuring intracellular superoxide anions, $2 \mathrm{~mL}$ of $10 \mu \mathrm{M}$ DHE was added into the dish, and cells were incubated at $37{ }^{\circ} \mathrm{C}$ and $5 \% \quad \mathrm{CO}_{2}$ for $30 \mathrm{~min}$. Cells were then harvested and resuspended. To measure the intracellular superoxide anion, cell samples were analyzed at $488 \mathrm{~nm}$ by FACS.

Statistical Analysis. Experimental results were presented as the mean \pm standard derivation of three parallel measurements. The $p$ values less than 0.05 were regarded as significant differences, and the $p$ values less than 0.01 were very significant differences.

\section{RESULTS AND DISCUSSION}

Composition Analysis of Buckwheat Sprouts. The general composition of common buckwheat sprouts (CBS) and tartary buckwheat sprouts (TBS) were measured, and results are shown in Table 1. During cultivation, it was observed that CBS, especially their stems and leaves, were thicker and stronger than TBS. The results of analyses revealed that CBS had higher contents of crude protein, ash, and crude fat than TBS $(P<$ $0.05)$. However, the content of crude fiber was not significantly different between these two types of buckwheat sprouts $(P=$ 0.84 ). It has been reported that common buckwheat grain has more dietary fiber and less ash than tartary buckwheat grain and that tartary buckwheat bran has more protein content than tartary buckwheat bran (10).

Phenolic Compounds of Ethanol Extracts of Buckwheat Sprouts. The phenolic compounds in the ethanol extracts of CBS and TBS were analyzed by HPLC, and their chromatograms are shown in Figure 1. Four flavonoids, including rutin, isoorientin, vitexin, and isovitexin, were found in the ethanol extract of CBS, whereas three flavonoids, rutin, quercitrin, and quercetin, were found in TBS. Among these compounds, rutin was the major antioxidant component in both types of buckwheat sprouts. It is noteworthy that TBS contains only three closely related flavonoids. Rutin is a glycoside comprised of the flavonol quercetin and the disaccharide rutinose, and the glycoside quercetrin is comprised of quercetin and rhamnose. All of them show remarkable antioxidant, anti-inflammatory, and anticancer activities. The ethanol extracts of TBS contains $655.82 \mathrm{mg} / \mathrm{g}$ of rutin, approximately 5 fold of the rutin content in the ethanol extracts of CBS (Table 2).

Antioxidant Capacity of Ethanol Extracts of Buckwheat Sprouts. The reducing power of the ethanol extracts from CBS and TBS were shown in Figure 2A. Results suggested that the higher the concentration of buckwheat sprout ethanol extracts, the higher their reducing power. The TBS ethanol extract had a higher reducing power than that of $\operatorname{CBS}(P<0.01)$. At a concentration of $5 \mathrm{mg} / \mathrm{mL}$, the reducing power of the ethanol extracts of buckwheat sprout was even higher than that of the ascorbic acid (data not shown). As shown in Figure 2B, the buckwheat sprout ethanol extracts had satisfactory scavenging effects on DPPH radicals. At low concentration $(1.25 \mathrm{mg} / \mathrm{mL})$ the TBS ethanol extracts had higher scavenging effects on DPPH radicals than that of CBS $(P<0.01)$. At a concentration of 5 $\mathrm{mg} / \mathrm{mL}$, the clearance of DPPH radicals for both TBS and CBS were approximately $88 \%$. Ascorbic acid had a much higher free radical scavenging activity, and it reached approximately $93.1 \%$ at a concentration of $0.3 \mathrm{mg} / \mathrm{mL}$. Similarly, the superoxide anion scavenging activity of TBS ethanol extracts was higher than that of CBS ethanol extracts $(P<0.01)$ (Figure 2C). At a concentration of $5 \mathrm{mg} / \mathrm{mL}$, the ethanol extracts of TBS had a $19.1 \%$ clearing capacity, whereas CBS ethanol extracts had a value of $11.0 \%$ clearing capacity. It was also found that ascorbic acid had a relatively higher superoxide anion scavenging activity, which was approximately $45.0 \%$ at a concentration of $5 \mathrm{mg} / \mathrm{mL}$.

Although the flavonoids, in general, possess ideal structure for antioxidant activity, the differences in chemical structures of different flavonoids would affect their antioxidant activities. It is known that the 3-OH group on the $\mathrm{C}$ ring plays an important role in flavonoid antioxidant activity, and maximum effectiveness for radical scavenging requires a $3-\mathrm{OH}$ attached to the 2,3double bond (17). However, the major flavonoids in TBS, including rutin, quercetin, and quercitrin, all had their 3-OH group in the $\mathrm{C}$ ring blocked by rutinose, glucose, or rhamnose. Although the glycosylation would reduce the TBS flavonoid antioxidant activity, the presence of the two adjacent $\mathrm{OH}$-groups in the ortho-diphenolic arrangement in the B ring certainly enhances their activity. The CBS flavonoids, including vitexin and isovitexin, have a lone $4^{\prime}-\mathrm{OH}$ group in the $\mathrm{B}$ ring and, thus, have lower antioxidant activity.

As shown in Figure 2D, the ethanol extracts of buckwheat sprouts had satisfactory chelating effects on ferrous ions, and the CBS chelating effects were greater than that of TBS $(P<$ $0.01)$. At a concentration of $1.25 \mathrm{mg} / \mathrm{mL}$, the CBS ethanol extracts had a $68.8 \%$ chelating effect, as compared with $45.0 \%$ in TBS. The two major points of attachment of ferrous ions to the flavonoids of buckwheat sprouts would be the $3^{\prime}$ and $4^{\prime}-$ dihydroxy groups in the $\mathrm{B}$ ring, the 4-keto in the $\mathrm{C}$ ring, and $5-\mathrm{OH}$ in the A ring. It is suspected that the glycosylation at $3-\mathrm{OH}$ in the $\mathrm{C}$ ring of flavonoids greatly reduces TBS metal chelating ability. As for ascorbic acid, the chelating effect on metal ions was too weak to be detected.

Effects of Buckwheat on Cell Survival Test (MTT Assay). The cell survival test of HepG2 cells treated with different concentrations (at $0.05,0.1,0.2,0.5$, and $1 \mathrm{mg} / \mathrm{mL}$ ) of buckwheat sprouts ethanol extracts for $24 \mathrm{~h}$ were examined, and results are shown in Figure 3. The relative MTT activity of cells treated with 0.5 and $1 \mathrm{mg} / \mathrm{mL}$ of CBS ethanol extracts were 65.39 and $64.15 \%$, respectively, whereas those of TBS 

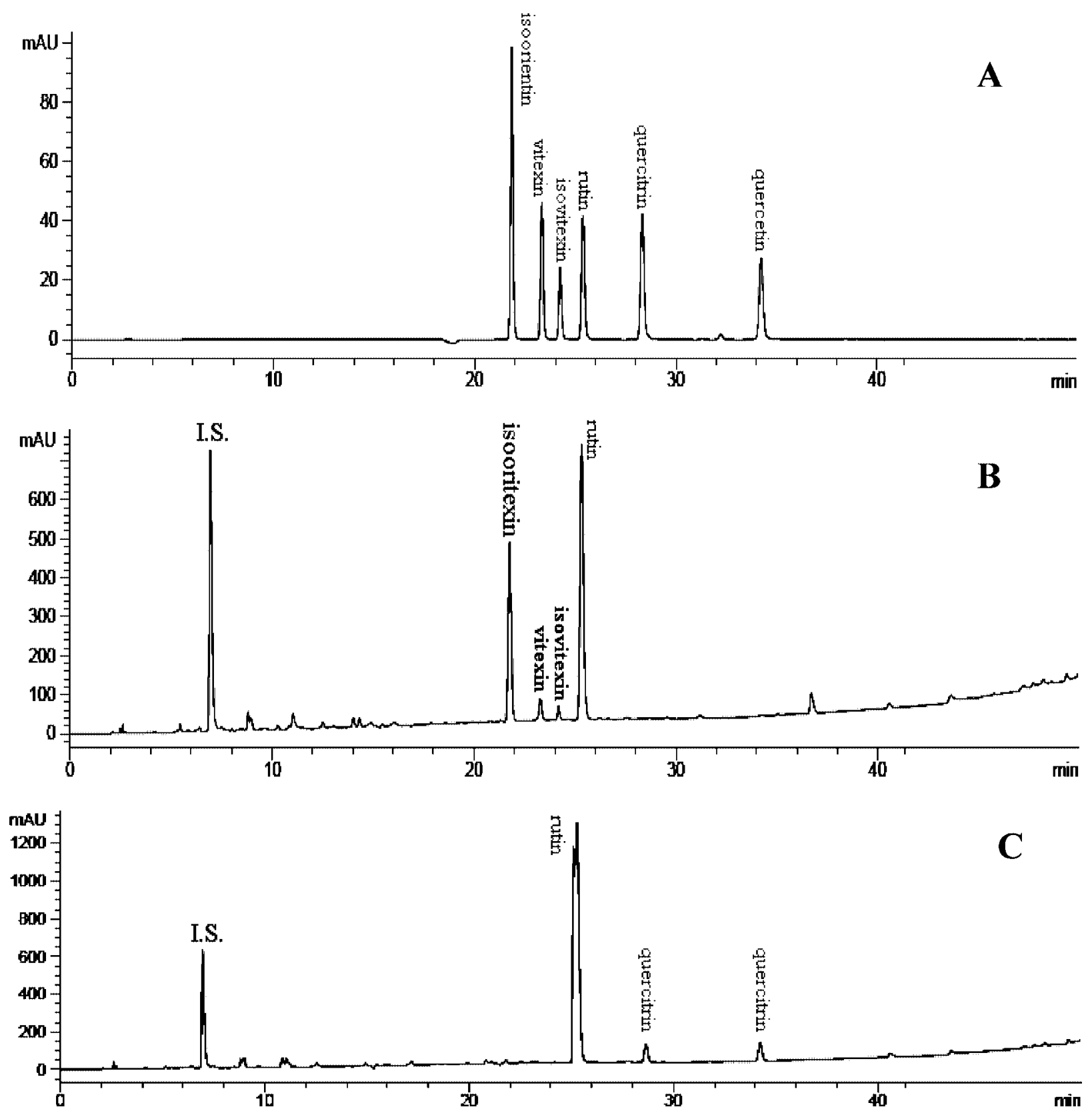

Figure 1. HPLC of CBS and TBS ethanol extracts. (A) Standards, (B) CBS, and (C) TBS; I.S., internal standard, pyrogallol.

Table 2. Flavonoids Contents in the Ethanol Extracts of CBS and TBS ${ }^{a}$

\begin{tabular}{|c|c|c|c|c|c|c|}
\hline components (mg/g dry weight) & rutin & isoorientin & vitexin & isovitexin & quercitrin & quercetin \\
\hline
\end{tabular}

\footnotetext{
${ }^{a}$ Each value was expressed as the mean \pm standard deviation $(n=3)$. ND: not detected. Values within a column superscripted with different letters were significantly different $(P<0.05)$.
}

ethanol extracts were $65.66 \%$ and $52.65 \%$, respectively $(P<$ 0.01 ). TBS inhibited the growth of HepG2 cells more effective than CBS, possibly because of its quercetin content, which is absent in CBS. Alia et al. (18) reported the effects of rutin and quercetin on cell growth and antioxidant activity of HepG2 cells. They found that cells were damaged even when treated with low dose of quercetin, but rutin had no cytotoxic effect on HepG2 cells at any dose for $24 \mathrm{~h}$ treatment. In this study, the cell survival rate was greater than $90 \%$ if the HepG2 cells were treated with buckwheat sprout ethanol extracts in the range of
$0.05-0.2 \mathrm{mg} / \mathrm{mL}$. Therefore, $0.2 \mathrm{mg} / \mathrm{mL}$ of the extracts was used to study their effects on antioxidant system in HepG2 cells for the following experiments.

Effects of Buckwheat on Intracellular Peroxide and Superoxide Anions in HepG2 Cells. Production of intracellular peroxide in HepG2 cells treated with $0.2 \mathrm{mg} / \mathrm{ml}$ of ethanol extracts of buckwheat sprouts for 3-12 h are shown in Figure 4. The production of intracellular peroxide in HepG2 cells after treatment with the TBS ethanol extracts for $3 \mathrm{~h}$ was significantly inhibited $(P<0.05)$, but it was not inhibited by that of CBS. 

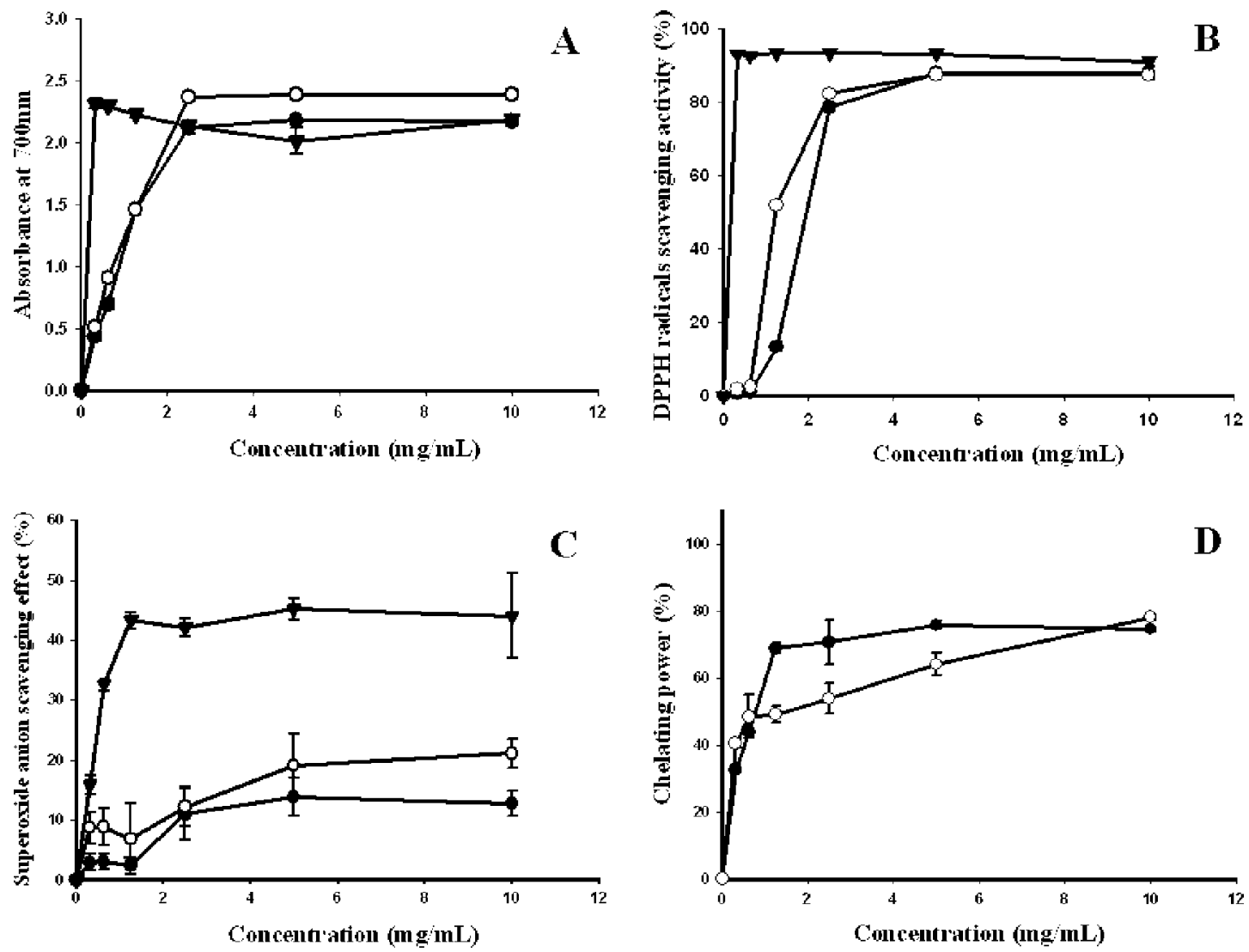

Figure 2. Antioxidant activities of CBS and TBS ethanol extracts. (A) Reducing power, (B) DPPH radical scavenging activity, (C) superoxide anion scavenging activity, and (D) Ferrous ion chelating power. (--) Common buckwheat sprouts, $\left(-\mathrm{O}^{-}\right)$tartary buckwheat sprouts, $(-\mathbf{\Delta}-)$ ascorbic acid.

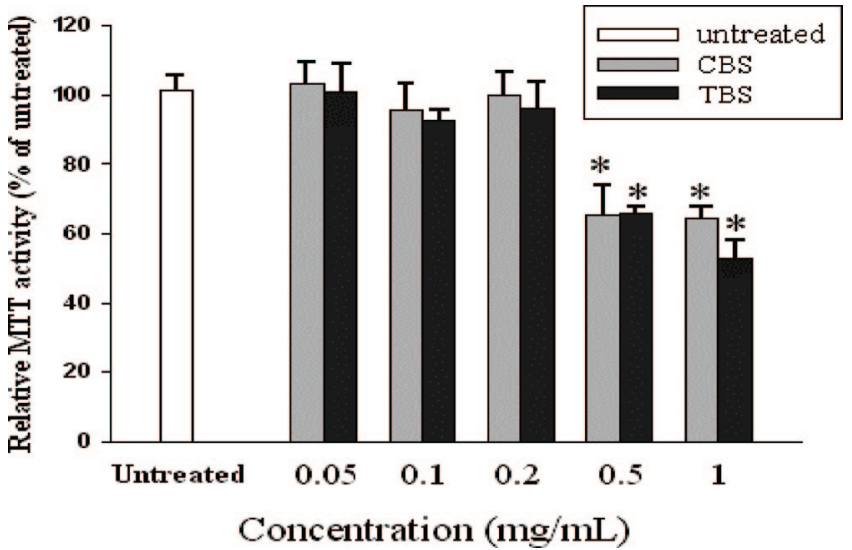

Figure 3. Dose-effects of CBS and TBS ethanol extracts on relative MTT activity in HepG2 cells. An asterisk indicates that the values are significantly different from untreated cells $(P<0.05)$.

As the treatment increased to $6 \mathrm{~h}$, the production of intracellular peroxide in HepG2 cells reached to their lowest points for both TBS and CBS treatments, $66.0 \%$ and $76.5 \%$, respectively. However, the inhibitory effects of TBS and CBS extracts on production of intracellular peroxide became less effective after $9 \mathrm{~h}$.

The intracellular superoxide anions of HepG2 cells treated with $0.2 \mathrm{mg} / \mathrm{mL}$ of buckwheat sprout ethanol extracts for 3-12 $\mathrm{h}$ are shown in Figure 5. Compared to untreated cells, the intracellular superoxide anions in CBS and TBS treated cells were significantly lower $(P<0.05)$ for $6-9 \mathrm{~h}$. However, there was no significant difference between untreated and treated cells after $12 \mathrm{~h}$, and this data is consistent with the effect of buckwheat sprouts on intracellular peroxide as described above.

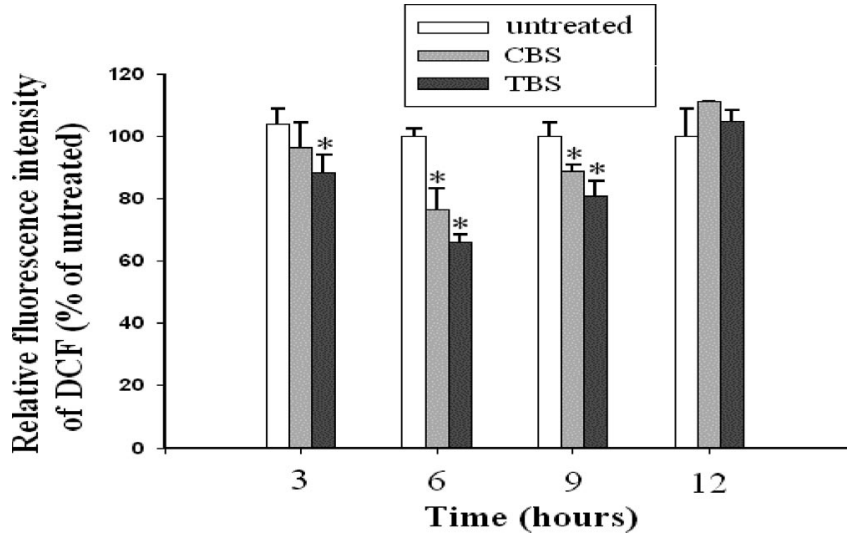

Figure 4. Effects of CBS and TBS ethanol extracts $(0.2 \mathrm{mg} / \mathrm{mL})$ on the production of intracellular peroxide in HepG2 cells. An asterisk indicates that the values are significantly different from untreated cells $(P<0.05)$.

It appeared that both TBS and CBS could protect HepG2 cells from antioxidative attack, and TBS was more effective than CBS. Alia et al. (19) also used human hepatoma HepG2 cells to study the antioxidant effects of quercetin and rutin, and they found that high doses of quercetin increased glutathione concentration, whereas rutin decreased the intracellular GSH at its highest concentration. Both quercetin and rutin decreased malondialdehyde and ROS generation in cells pretreated with tert-butyl hydroperoxide (t-BOOH). Kampkotter and co-workers (20) investigated the protective effects of quercetin and rutin on stress resistance in the organism Caenorhabditis elegans and found that the antioxidative activity of quercetin was higher than that of rutin under conditions of induced oxidative stress. 


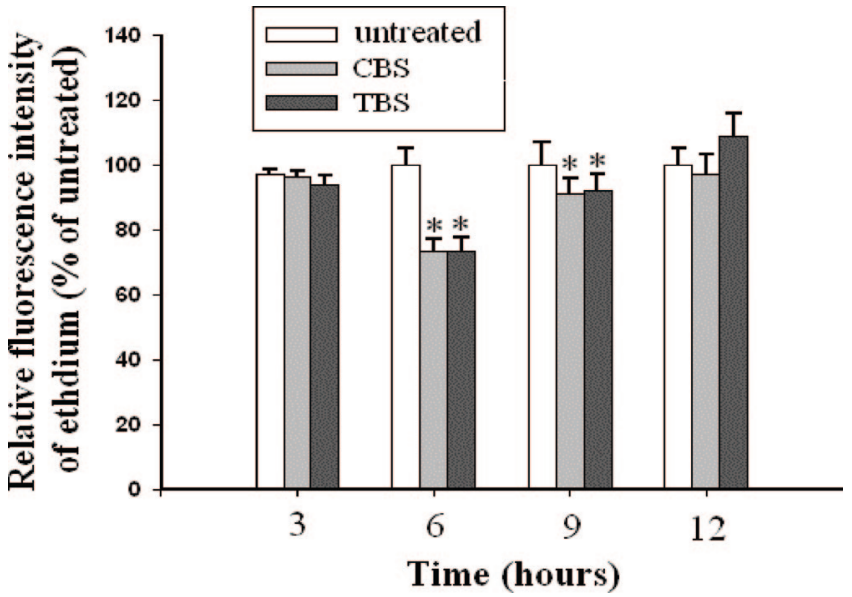

Figure 5. Effects of CBS and TBS ethanol extracts $(0.2 \mathrm{mg} / \mathrm{mL})$ on production of intracellular superoxide anions in HepG2 cells. An asterisk indicates that the values are significantly different from untreated cells $(P$ $<0.05)$.

They suggested that, although rutin possesses antioxidative activity, quercetin acts as an antioxidant as well as a modulator of cellular signaling processes to exert its oxidative stress protection effect. In this study, it was found that the content of rutin in TBS was higher than that in CBS, and quercetin only existed in TBS (Table 2). Therefore, the finding that TBS is more effective in reducing the cellular oxidative stress in the human hepatoma HepG2 cells than CBS may be attributed to its higher rutin and quercetin contents.

This research found that rutin was the major flavonoid in both CBS and TBS and that it played an important role in the antioxidant capacity of buckwheat sprouts. TBS contained 5 fold the amount of rutin than CBS. Other than rutin, the major flavonoids in TBS include quercetin and quercitrin, and they all have two adjacent $\mathrm{OH}$-groups in the ortho-diphenolic arrangement in the $\mathrm{B}$ ring. The flavonoids in $\mathrm{CBS}$, including vitexin and isovitexin, have a lone $4^{\prime}-\mathrm{OH}$ group in the $\mathrm{B}$ ring, and, thus, TBS in general had a higher antioxidant capacity than CBS. The effects of buckwheat sprouts on the antioxidant system in HepG2 cells revealed that both buckwheat sprouts could significantly decrease the production of intracellular peroxide as well as remove the intracellular superoxide anions. However, probably due to the fact that the content of rutin in TBS was higher than that in CBS and that quercetin only existed in TBS, TBS was found to be more effective in reducing the cellular oxidative stress in the human hepatoma HepG2 cells than CBS. It appears that the tartary buckwheat sprouts should be consumed more often because of its health-promoting properties. Cooking methods should be developed to render its bitter taste more tolerable.

\section{LITERATURE CITED}

(1) Gutteridge, J. M. C.; Halliwell, B. The measurement and mechanism of lipid peroxidation in biological systems. Trends. Biochem. Sci. 1990, 15, 129-135.

(2) Li, S. Q.; Zhang, Q. H. Advances in the development of functional food from buckwheat. Crit. Rev. Food Sci. Nutr. 2001, 41, 451464.

(3) Oomah, B. D.; Mazza, G. Flavonoids and antioxidative activities in buckwheat. J. Agric. Food Chem. 1996, 44, 1746-1750.
(4) Dubber, M. J.; Sewram, V.; Mshicileli, N.; Shephard, G. S.; Kanfer, I. The simultaneous determination of selected flavonol glycosides and aglycones in Ginkgo biloba oral dosage forms by high-performance liquid chromatography-electrospray ionizationmass spectrometry. J. Pharm. Biomed. Anal. 2005, 37, 723-731.

(5) Joubert, E.; Winterton, P.; Britz, T. J.; Ferreira, D. Superoxide anion and $\alpha, \alpha$-diphenyl- $\beta$-picrylhydrazyl radical scavenging capacity of rooibos (Aspalathus linearis) aqueous extracts, crude phenolic fractions, tannin and flavonoids. J. Food Res. Intern. 2004, 37, 133-138.

(6) Peng, J.; Fan, G.; Hong, Z.; Chai, Y.; Wu, Y. Preparative separation of isovitexin and isoorientin from Patrinia villosa Juss by high-speed counter-current chromatography. J. Chromatogr. A. 2005, 1074, 111-115.

(7) Xiaoling, H.; Xie, Z. N.; Na, Y.; Jinliang, L. Outline of the investigation on the leaf of $\mathrm{F}$. tataricum by the means of traditional Chinese medicine and western modern medicine. In Proceedings of the 5th international symposium on buckwheat, 20-26 August, Taiyuan, China. 1992, pp 470-476.

(8) Fabjan, N.; Rode, J.; Kosir, I. J.; Zhang, Z.; Kreft, I. Tartary buckwheat (Fagopyrum tataricm Gaertn.) as a source of dietary rutin and quercitrin. J. Agric. Food Chem. 2003, 51, 6452-6455.

(9) Bonafaccia, G.; Gambelli, L.; Fabjan, N.; Kreft, I. Trace elements in flour and bran from common and tartary buckwheat. Food Chem. 2003, 83, 1-5.

(10) Bonafaccia, G.; Marocchini, M.; Kreft, I. Composition and technological properties of the flour and bran from common and tartary buckwheat. Food Chem. 2003, 80, 9-15.

(11) Official Methods of Analysis, 16th ed.; Association of Official Analytical Chemists: Washington DC, 1995.

(12) Steadman, K. J.; Burgoon, M. S.; Lewis, B. A.; Edwardson, S. E. R.; Obendorf, R. L. Minerals, phytic acid, tannin and rutin in buckwheat seed milling fractions. J. Sci. Food Agric. 2001, $81,1094-1100$.

(13) Oyaizu, M. Antioxidative activity of browning products of glucosamine fractional by organic solvent and Thin layer chromatograph. Nippon Shokuhin Kogyo Gakkaish. 1986, 35, 771775 .

(14) Shimada, K.; Fujikawa, K.; Yahara, K.; Nakamura, T. Antioxidative properties of xanthan on the autoxidation of soybean oil in cyclodextrin emulsion. J. Agric. Food Chem. 1992, 40, 945948.

(15) Dinis, T. C.; Maderia, V. M.; Almeda, L. M. Action of phenolic derivatives (acetaminophen, salicylate and 5-aminosalicylate) as inhibitors of membrane lipid peroxidation and as peroxyl radical scavengers. Arch. Biochem. Biophy. 1994, 315, 161-169.

(16) Liu, F.; Ooi, V. E. C.; Chang, S. T. Free radical scavenging activity of mushroom polysaccharide extracts. Life Sci. 1997, 60, 763771.

(17) Rice-Evans, C.; Miller, N. J.; Paganga, G. Structure antioxidant activity relationships of flavonoids and phenolic acids. Free Rad. Bio. Med. 1996, 20, 933-956.

(18) Alia, M.; Raquel, M.; Ramos, S.; Lecumberri, E.; Bravo, L.; Goya, L. Influence of quercetin and rutin on growth and antioxidant defense system of a human hepatoma cell line (HepG2). Eur. J. Nutri. 2006, 45, 19-28.

(19) Alía, M.; Ramos, S.; Mateos, R.; Granado-Serrano, A. B.; Bravo, L.; Goya, L. Quercetin protects human hepatoma HepG2 against oxidative stress induced by tert-butyl hydroperoxide. Toxicol. App. Pharmacol. 2006, 110-118.

(20) Kampkotter, A.; NKwonkam, C. G.; Zurawski, R. F.; Timpel, C.; Chovolou, Y.; Watjen, W.; Kahl, R. Investigations of protective effects of the flavonoids quercetin and rutin on stress resistance in the model organism Caenorhabditis elegans. Toxicology 2007, 234, 113-123.

Received for review August 5, 2007. Revised manuscript received October 28, 2007. Accepted October 30, 2007.

JF072347S 